\title{
NEWS
}

\section{A Selection of News from the Institute}

Details of news and events can be found throughout the year on the Institute's website at http://www.ucl.ac.uk/archaeology/news-events.

The Gordon Childe Lecture, 2018: Professor Kristian Kristiansen: 'Towards a new European Prehistory - genetics, archaeology and language'

Mike Parker Pearson

UCL Institute of Archaeology

m.parker-pearson@ucl.ac.uk

Gordon Childe, director of the Institute of Archaeology in 1946-1956, was the foremost authority of his age on European prehistory so it was a pleasure to hear Kristian Kristiansen set out his vision for a new framework more than half a century later. Childe had established a prehistory of Europe on the basis of archaeological discoveries, relative dating, typological analysis and linguistic analysis; his ground-breaking conclusions were later to be questioned and even discredited by his successors, using the absolute dating of radiocarbon chronologies and dismissing his migrationbased explanations of culture change.

Kristian Kristiansen's lecture revealed what is possible when archaeology is complemented by new scientific methods such as isotopic analysis and genetics, notably the recent advances in recovering human genomes from human skeletal remains. Childe and his generation had been able only to infer genetic or 'racial' characteristics from shared forms of material culture, leading to ultimately spurious and circular notions of interpreting identity - treating 'pots as people'. But now genetic ancestry can be studied as an independent variable, distinct from stylistic patterns in prehistoric artefacts and practices. Combined with isotope analysis to recover patterns of lifetime movement by individuals in prehistory, these new techniques provide powerful new tools for identifying population mobility and migration in the distant past.

These recent scientific developments are, for Kristiansen, components of a new paradigm shift in archaeology, nearly 40 years after the last one. That was post-processual archaeology, a reaction to the New Archaeology of the 1960s and 1970s, which had previously deconstructed much of Childe's 'culture history' approach. Not everyone would agree that advances in method alone - without similar changes in epistemology and explanation can be considered as constituting a paradigm change but such doctrinal disagreements need not affect our appreciation of Kristiansen's new framework for prehistoric Europe.

Recent research into ancient DNA has revealed that farming was spread across Europe, beginning 10,000 years ago, from its origins in the Middle East by groups of farmers who mixed their genes to varying degrees with indigenous hunter-gatherers during the gradual expansion westwards and northwards, confirming long-held notions of demic diffusion that survived the New Archaeological demolition. What has been even more of a revelation is the confirmation of Copper Age migrations, from $3000 \mathrm{BC}$ onwards, westward across Europe from the Pontic steppe east of the Black Sea. Kristiansen's team of geneticists and archaeologists have been in the forefront of this research, tying it in with linguists' 
identification of this migration as the dispersal of proto-Indo-European languages.

For those in the audience familiar with the history of archaeology, such claims no doubt had the ring of familiarity because Childe and other culture-historians identified these Copper Age migrations long ago. Their interpretations fell out of favour with the New Archaeology and were substantially dismissed until this new research. Showing remarkable prescience, Kristiansen had revived the idea of these Copper Age migrations as early as 1989 in an article on the Corded Ware culture of northern Europe and Scandinavia.

Kristiansen has always been a 'big picture' prehistorian, as is evident in books such as Europe Before History and The Rise of Bronze Age Society, and he treated us to a similarly broad canvas of Eurasian social transformation during the fourth and third millennia BC. Despite the 'muteness' of the archaeological record, he convincingly portrayed how archaeology, genetics and linguistics could be worked together to produce a new understanding of how patrilineal exogamous groups expanded westwards to bring IndoEuropean language and social structures to the farming societies of western Europe. His claim is that we know a lot more about these prehistoric people than we have supposed.

Whilst not all of these claims can be considered to be nailed-down fact - and Kristiansen is the first to admit that this is a model to be tested the vision that he has set out is provocative and challenging. It will help to guide our research into the European Copper Age for years to come.

I was probably not the only member of the audience to wonder what Childe would have made of it all these years later - he would, I am sure, have been delighted to learn that the genetics and isotopic evidence broadly back up and develop further his prematurely discredited theories. But I suspect he would have been humble enough to make no bones about it. He would surely have recognized that this is a very exciting time to be researching European prehistory. Kristiansen's lecture left us in no doubt of that.

\section{UCL and The British Museum: Exploring and Enhancing Connections}

\author{
David Wengrow and Carl Heron \\ UCL Institute of Archaeology and The British \\ Museum \\ d.wengrow@ucl.ac.uk \\ cHeron@britishmuseum.org
}

Ties between UCL and The British Museum have never been closer than they are today. Much of this collaborative activity goes on beyond the public gaze, and even colleagues are not always aware of the sheer breadth of interaction that exists between Bloomsbury's two leading cultural heritage institutions. The history of these links runs deep, right back in fact to the founding of UCL in 1826, and is built in to their respective collections. Today, UCL alumni hold an impressive range of positions at The British Museum as conservators, research scientists, curators and Keepers of regional collections from all over the globe. Recent collaborations cover an extraordinary range of topics, from the documentation of Hans Sloane's catalogues to the Sierra Leone Heritage Project, and 'MicroPasts', a joint enterprise that pioneered digital crowd-sourcing of archaeological data. The two institutions also have an impressive record of holding collaborative doctoral awards, and have been jointly training conservators for many decades.

Despite all this, there has never been a focussed discussion of the relationship between UCL and The British Museum. With the exciting development of the 'Knowledge Quarter', still in early stages, but intended to forge closer links between heritage and education institutions across Bloomsbury, now seemed an excellent time to get that discussion in motion. With this aim, staff from UCL's Institute of Archaeology partnered up with their opposite numbers at the BM to undertake a year-long review of our joint activities, with generous funding and support from UCL Innovation \& Enterprise (Knowledge Exchange and Innovation Fund). Our joint project runs for the academic session 201718 , offering opportunities for staff from both 
institutions to showcase existing collaborations and run workshops to explore future joint projects. The venture will also produce a portfolio of recent and existing relationships between the two institutions for publication and consultation in thinking ahead to the possibilities for reciprocal training arrangements, joint research and funding applications.

Our joint committee comprises, from the IoA: David Wengrow (Project Lead), Sirio Canós-Donnay (Assistant Project Coordinator), Corisande Fenwick (Archaeology), Dorian Fuller (Archaeological Science), Renata Peters (Conservation), and Theano Moussouri (Museum Studies). And from the BM: J.D. Hill (Research Manager), Carl Heron (Director of Scientific Research), Beccy Scott (Britain, Europe and Prehistory), and Anna Buelow (Head of Conservation). John Giblin, a UCL alumnus and former Head of Africa at the BM, was initially part of this group, but has moved on, having since taken up a new position as Keeper of World Cultures at National Museums Scotland. He is replaced by Jonathan Tubb (Keeper of Middle East).

'UCL \& The British Museum' launched with an exchange of hospitality. The British Museum hosted UCL staff from a range of departments at a private morning showing of Scythians: Warriors of Ancient Siberia, and we reciprocated with a New Year's Party, which brought many UCL alumni back to their former academic home. Both were great occasions, which illustrated the sheer density of personal and professional connections between our two institutions. They also established the ethos of this project, which is very much to work from the bottom up, building on and fostering existing relationships, while recognising that some others may work better in their current, loose form. A project website (https://www.ucl.ac.uk/archaeology/research/ directory/ucl-british-museum/) will assist with the collection of data on joint research and training activities, and we invite both UCL and BM staff to use it as a route for submitting information to our growing inventory.

Our first major joint academic event took place on May 25 $5^{\text {th }}$, 2018: 'UCL and The British Museum in Africa and the Middle East: Current
Projects and Future Agendas' (Figure 1). This was a public event, jointly funded with UCL Global Engagement, which brought together some fourteen researchers from both institutions, and also from the Victoria and Albert Museum, to examine future directions in African and Middle Eastern studies. Special attention was given to the changing context of fieldwork-based disciplines, collections, and archives. In particular, the conference considered how the global ambitions of major metropolitan university and museums are to be reconciled with a problematic legacy of colonialism in these regions, with keynote talks from Elena Fiddian-Qasmiyeh (UCL Geography, and Co-Director of the Migration Research Unit) and Sada Mire (University of Leiden, and alumna of the UCL Institute of Archaeology). This event attracted over a hundred attendees, around half of them members of the public, and has already generated important new synergies in the area of Islamic heritage, archaeology, and refugee studies, among others.

Three further events took place through the late Spring and into early Summer. Two workshops, organised by Dorian Fuller, Ian Freestone (IoA), Andrew Meek (BM) and Carl Heron (BM) explored the unrivalled potential of Archaeological Science - including both materials analysis and bioarchaeological research - in the Bloomsbury are. The first, on May $31^{\text {st }}$, focussed on 'Diet, Health, and Environment', was hosted at the British Museum, with contributions from over fifteen researchers. Important synergies were identified in growth areas of laboratorybased research such as proteomics, isotope and dental studies, and the reconstruction of ancient food and climate systems. A second event, 'Material Matters' at the IoA, took place on $12^{\text {th }}$ June, with thirteen contributions focussing on technical studies, imaging, and microscopy as tools for archaeological analysis, with case studies ranging from China to Sudan. There was also focussed discussion of new laboratory facilities at both the IoA and the BM, and the potential for future interaction around specific research topics and grant applications. 


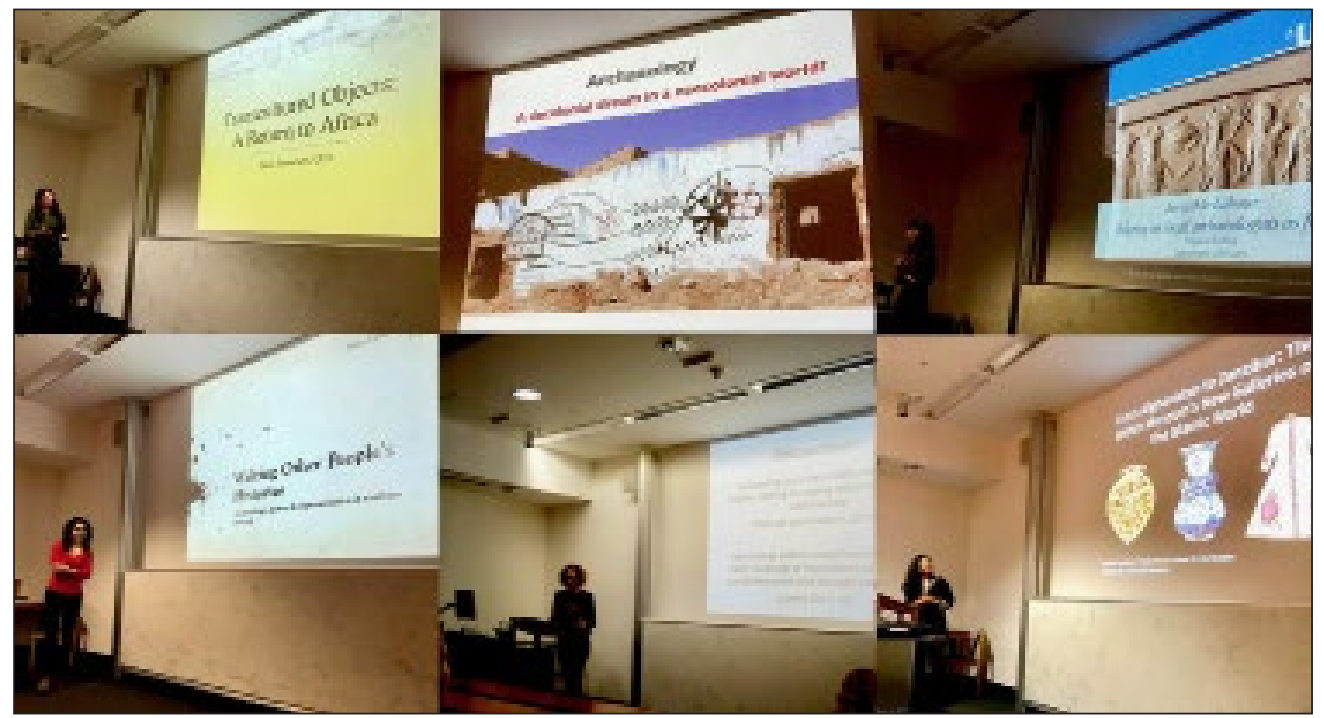

Figure 1: Presentations at the 'UCL and The British Museum in Africa and the Middle East: Current Projects and Future Agendas' conference held in May 2018 (Photo: Elena FiddianQasmiyeh/Refuge in a Moving World network).

Internationally, the BM and UCL represent one of the largest concentrations of expertise in this area, and share a history of collaboration dating back to Mortimer Wheeler. A final UCL/British Museum workshop held on the $18^{\text {th }}$ June $18^{\text {th }}-$ 'What Does the Future hold for Conservation' - brought together conservators and conservation students to consider future directions for the conservation profession. The aim was to address challenges conservation professionals and students are likely to confront in the near future, such as the use of new technologies in conservation, the need to increase diversity, public outreach, issues relating to conservation skills (diversity vs specialisation) and employability.

As the UCL-BM project progresses, we will work towards enhancing the public profile of our collaborations, and also creating a legacy through strategic discussion of areas where collaboration may not yet be reaching its full potential. This is always with an eye to two important realities. The first is that the British Museum is a national institution, which cannot unduly privilege any one university. The second is that there is no getting around the facts of geographical proximity, the economies of scale this creates, the unique density of historical and professional ties between UCL and the $\mathrm{BM}$, and the extraordinary range of opportunities this creates for cooperation on matters of research, public policy, and fulfilling our primary common goal, which is to place our joint resources and expertise at the disposal of London's extraordinary public and of all who visit the city from the around the world.

\section{International Research Centre for Silk Roads Archaeology \& Heritage}

Tim Williams, Gai Jorayev and Rui Pang UCL Institute of Archaeology

tim.d.williams@ucl.ac.uk

g.jorayev@ucl.ac.uk

rui.pang@ucl.ac.uk

A new partnership between UCL Institute of Archaeology (IoA) and North-West University (NWU), Xi'an, has led to the establishment of an International research centre for Silk Roads Archaeology \& Heritage (SRAH). The Centre was launched by the Director Prof 
Sue Hamilton, Prof Dorian Fuller and Dr Yijie Zhang from the IoA, and Prof Duan Qingbo, at NWU in Xi'an on the 13th April 2018 (Figure 2). The Centre, directed by Tim Williams at the IoA and Prof Duan Qingbo at NWU, aims to act as a transformative base for international Silk Roads studies, drawing together disparate strands of current work, building international collaborations, and undertaking groundbreaking new research on a phenomenon that transformed the world. Further details about the Centre can be found at: http://www.ucl. ac.uk/archaeology/research/silk-roads.

Both institutions have a long history of Silk Roads archaeology and research. In 1938, NWU excavated the tomb of Zhang Qian, and since then their archaeologists have carried out numerous excavations along the Silk Roads. Silk Roads archaeology, preservation technologies, and cultural heritage management are now major research directions for NWU. Similarly, the IoA have been working in Western and Central Asia for many years, including the long-running research project at the Silk Roads city of Merv in Turkmenistan (http://www.ucl.ac.uk/archaeology/research/ merv). Work has also been undertaken for the
UNESCO serial nomination of the Silk Roads, including the ICOMOS thematic study of the Silk Roads (Williams 2014), which created the platform for the current trans-national nominations. Recently the Maritime Silk Routes have received growing attention, bringing an even wider range of potential partners to the debate. The IoA hosted a UNESCO expert meeting in 2017 and is currently working on the nomination strategy.

The international impact of the Silk Roads extended far beyond trade; whether local or trans-regional, whether low value bulk goods or prestige items. The significance and impact of the Silk Roads lay in the movement of ideas - technologies, artistic styles, belief systems, philosophies, languages, customs and legends - and, less welcome, the spread of infectious diseases, and the political struggles, sometimes violent, to control trade and manage the movement of people and ideas. The Centre will undertake comparative research to explore these changes, bringing the ebb and flow of empires and societies, the complexities of environmental adaption and response, the transmission of ideas, the impact of social change and the shaping of the modern world, to the widest possible audience.

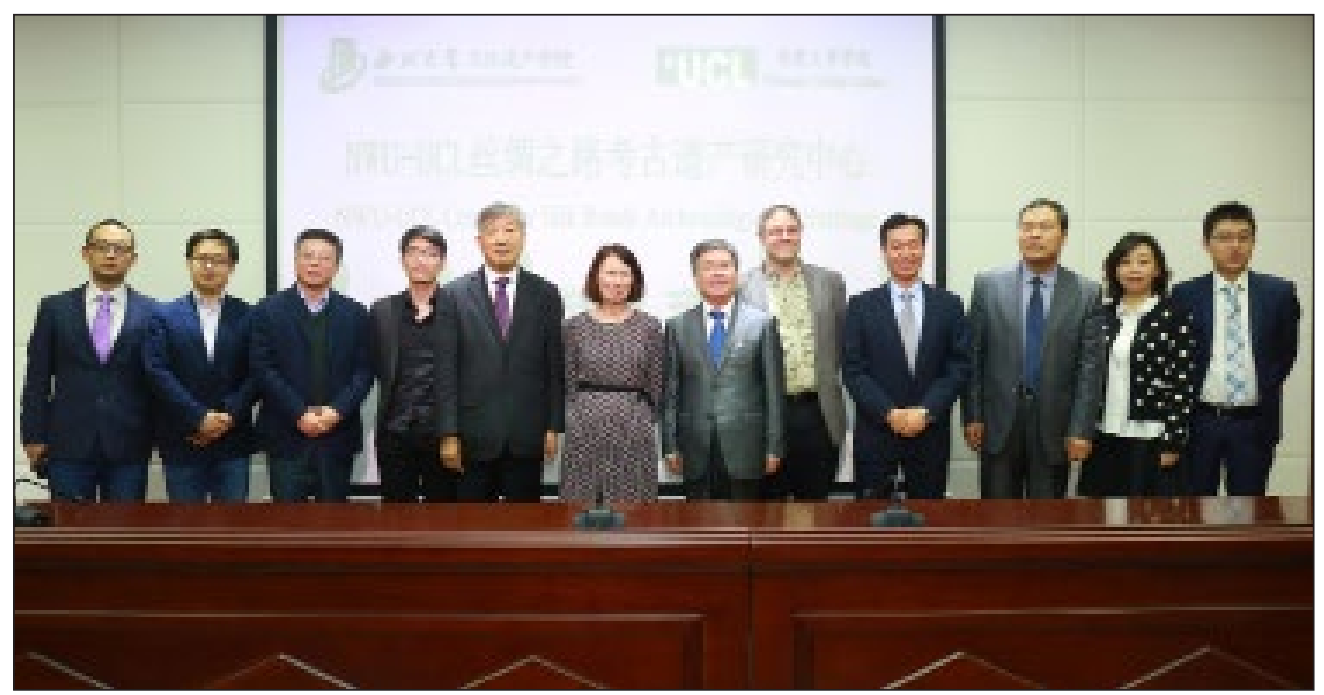

Figure 2: Representatives from UCL Institute of Archaeology and North-West University (NWU), Xi'an, at the launch of the new Silk Roads Archaeology \& Heritage research centre at NWU in April 2018 (Photo: Tim Williams). 
Currently extensive archaeological research is taking place along the Silks Roads, in part inspired by the nomination project of the Silk Roads to the UNESCO World Heritage list. The Centre hopes to help to draw attention to this growing wealth of scholarship, to promote wider dialogue, debate and development. To assist in this, the Centre is establishing a new Open Access peer reviewed Silk Roads Journal, to be launched in late 2018.

The research focus of the SRAH Centre will be both to undertake cutting-edge comparative research, and projects to disseminate information and build collaborations along the Silk Roads. Some research projects we are currently undertaking, or developing, include: the transition of the Late Antique city into the Islamic world; the trans-Himalayan and "Southern Silk Roads"; feeding Silk Roads communities (exploring the spread of agricultural products, techniques, and hydrological skills enabled societies to adapt to the complex environments along the Silk Roads); population changes and the scale of urbanism; the movement of peoples (least-cost path and adaptive networks); visualisation of Silk Road cities (light, heat, shade - understanding urban life and textures); rhythm analysis and urban morphology of the early Islamic city on the Silk Roads; the modern uses of the Silk Roads concept, including Central Asian nationalism, the Belt and Road Initiative, and heritage tourism; the management of remote Silk Roads sites in southern Xinjiang; and approaches to the sustainable management of the Tea and Horse routes in southern China.

Research projects aimed at building collaborations and synthesis are a major priority. Data sharing for the study of the Silk Roads is crucial, given the scale, complexity and chronological depth of the potential study areas. Digital data offers the potential of advancing our understanding of the complexity of the societies that lived along the Silk Roads through comparative research. The application of big data, especially remote sensing and environmental information, to understanding the Silk Roads (GPR,
Geophysics, Aerial photography, LiDAR, Satellite imagery, etc.) is vital. We are currently exploring collaborations with numerous agencies, such as the Digital Belt and Road Program (DBAR), with the support of the Chinese Academy of Sciences (Guo 2018), the International Institute for Central Asian Studies (IICAS) (http://www.unescoiicas.org/) and the ICOMOS International Conservation Center-Xi'an (IICC-X) (http:// www.iicc.org.cn/Channel.aspx?ChId=2) to develop effective means for sharing Silk Roads data. We are working towards an online open access Silk Roads Geographic Information System, as a platform for sharing and visualising digital data; a gazetteer of Silk Roads cities, as a point-in-time comprehensive review of the state of knowledge of Silk Roads cities; online bibliographic data on Silk Roads research (a multi-lingual system, especially focused on drawing attention to the wealth of scholarship from China and Central Asia); material culture on the Silk Roads (building on existing research to create networks of researchers exchanging data and providing scientific support to partners, particularly in Central Asian and South Asia, to assist in developing scientific approaches to the understanding of material cultures).

The SRAH centre will continue to promote the Central Asian seminar series, in association with the Association for Central Asian Civilizations \& Silk Road Studies (ACANSRS) (http://acansrs.org/) and in the coming year, new programmes and collaborations regarding the Maritime Silk Routes are being developed. We are very keen to hear from any potential partner and collaborators, across all areas of Silk Roads studies, in what we hope is an important new initiative for Silk Roads research.

\section{References}

Guo, H 2018 Steps to the digital Silk Road. Nature, 554: 25-27. DOI: https://doi. org/10.1038/d41586-018-01303-y

Williams, T 2014 Silk Roads: an ICOMOS Thematic Study. Charenton-le-Pont: ICOMOS. 